\title{
Chemical vegetable safety in China: "supermarketisation" and its limits
}

\author{
Lita Alita, Liesbeth Dries and Peter Oosterveer \\ Wageningen University and Research, Wageningen, Netherlands
}

\begin{abstract}
Purpose - The purpose of this paper is to analyze the process of supermarketization in the vegetable retail sector in China and its impact on food safety.

Design/methodology/approach - Data from food safety reports by the Chinese Food and Drug Administration (CFDA) are used to investigate the degree of vegetable safety in different value chain types. To assess the predictors of the degree of vegetable safety, a logistic regression model is applied.

Findings - Supermarketization has led to the reorganization of the vegetables provision system, through closer coordination along the supply chain and the use of secured production bases. We identify four types of vegetable value chains in China based on their form of coordination. Supermarkets improve vegetable safety even when they rely on external suppliers, but also wet markets perform significantly better than other smallscale retailers in terms of vegetable safety.

Originality/value - The study has expanded the knowledge of the supermarketization in urban China by collecting data from CFDA. Furthermore, the study used the theory of food value chain to understand determinant factors in securing food safety. Moreover, this study reveals that wet markets also have prospects in solving vegetable safety problems in China, especially in underdeveloped areas.
\end{abstract}

Keywords Supermarkets, Urban China, Food value chain, Wet market, Vegetable safety

Paper type Research paper

\section{Introduction}

Fresh vegetables have long been recognized as one of the most important food items in China. The typical Chinese diet is plant-based and thus differs from that of most Western populations (Cheng et al., 2016). Vegetable consumption per capita in China amounted to $447 \mathrm{~kg}$ in 2017, which is significantly higher than the average consumption per capita in the world $(134 \mathrm{~kg})(\mathrm{OECD}, 2018)$. China has emerged as the world's largest vegetable producer, with global output shares of more than $50 \%$ for vegetables (OECD, 2018). In addition, vegetables are among the top food categories in terms of expenditure in China. In 2014, an average Chinese household spent over 270 Euro to purchase fresh vegetables, which is almost $20 \%$ of the total annual expenditure on food (NBSC, 2017). Adequate consumption of vegetables is positively associated with better health from a nutritional point of view, according to WHO dietary guidelines (WHO, 2016). However, severe safety hazards associated with vegetables currently threaten public health in China.

(C) Lita Alita, Liesbeth Dries and Peter Oosterveer. Published in British Food Journal. Published by Emerald Publishing Limited. This article is published under the Creative Commons Attribution (CC BY 4.0) licence. Anyone may reproduce, distribute, translate and create derivative works of this article (for both commercial \& non-commercial purposes), subject to full attribution to the original publication and authors. The full terms of this licence may be seen at: http://creativecommons.org/licences/by/4.0/ legalcode

This work is part of the research program "Sustainable Natural Resource Management for Adequate and Safe Food Provision" with project number "PSA-SA-E-01", which is financed by the the Royal Netherlands Academy of Arts and Sciences (KWAW) and the Ministry of Science and Technology (MOST) in China.
Chemical vegetable safety in China

Received 20 August 2019 Revised 21 November 2019 17 January 2020

Accepted 13 February 2020 
Previous research has indicated the prevalence of food safety hazards in fresh vegetables in China (Gale and Hu, 2012; Zhao et al., 2018). The most grievous safety hazard for vegetables is the use of agricultural chemicals (Van Hoi et al., 2010; Zhao et al., 2018). Food contaminated by agricultural chemicals causes over 200,000 acute intoxications annually as per the Chinese Ministry of Health (Liu and Ma, 2016). When toxic chemicals are used for pest control, vegetables may be contaminated. China is the world's largest user of agricultural chemicals, applying more than $30 \%$ of fertilizers and pesticides globally on only $9 \%$ of the world's cropland (Wang et al., 2013). Consequently, vegetable safety hazards resulting from the use of agricultural chemicals are a critical issue in China.

The Chinese public authority has acknowledged the prevalence of vegetable safety hazards and implemented policies to resolve the problem since the 2000s (Zhou et al., 2015). Local governments have attempted to strengthen extension services that provide farmers with information on pesticide applications (Kirezieva et al., 2016). However, the governmental extension services have not sufficiently reduced the amount of pesticides applied in agriculture (Zhao et al., 2018). Previous research have confirmed that ineffectiveness of extension services is a common problem in developing countries due to the lack of funding and staff (Xu et al., 2008; Zhang et al., 2017).

In addition to reducing vegetable safety hazards by monitoring farmers, the government has attempted to moderate safety hazards by restraining vegetable retailers (Babcock, 2017). Traditionally, fresh vegetables in urban China are provided by stallholders in wet markets. Since the 2000s, local governments have tried to replace wet markets with supermarkets (Babcock, 2017). This replacement has been justified with multiple reasons. The most frequently used argument is the food safety issue. Supermarkets are considered instrumental for realizing food safety improvements by implementing private food safety management systems and maintaining food hygiene standards (Reardon and Timmer, 2012). A "supermarket chain" operates nationwide or at least provincewide, possesses a large number of stores and has the capability of integrating vertically into the value chain (Song et al., 2012). Through a preferential policy (known as the Dragon Head Companies Program), local governments selected and supported large-scale retail corporations as lead firms in the supply chain (Wang et al., 2013). The selected lead firms received privileged tax rates as well as access to low interest loans with favorable terms through China's Agricultural Development Bank (Babcock, 2017). With the support of local governments, the expansion of supermarkets has reshaped the food retail sector in China in recent decades. According to China's Ministry of Commerce, the supermarket share of vegetable retail sales comprised $20 \%$ of the market in 2013 and rose to $30 \%$ by 2017 (NBSC, 2017). The Global Agricultural Information Network (GAIN) claims that an even larger share of $40 \%$ of China's fresh vegetables was distributed by supermarkets in 2017 (Babcock, 2017).

The expansion of supermarkets has led to the reorganization of the vegetable provision system (Berger and van Helvoirt, 2018; Dries et al., 2004; Wertheim-Heck and Spaargaren, 2016). This development is also referred to as "supermarketization" (Reardon and Hopkins, 2006). Traditionally, vegetables in China are distributed through complex networks of farmer households, traders, intermediaries and stallholders in wet markets, grocery stores and supermarkets (Song et al., 2012). Following the expansion of supermarkets, traditionally organized distribution channels of vegetables have given way to direct sales and contract farming arranged by lead firms (Oosterveer, 2012; Timmer, 2009). Lead firms have established farm bases (also known as agricultural production bases) with specialized production and uniform management in terms of production and input use. Moreover, largescale supermarket chains have adopted a central coordinating role in food chains (Oosterveer, 2012). Reardon and Timmer (2012) claim that supermarket chains are capable of implementing private food safety management systems. On the other hand, they also express the concern that the supermarketization process in developing countries might differ 
from the process in developed countries (Reardon and Timmer, 2012). This concern is shared by Goldman (2001), who investigated supermarketization in developing countries and found that instead of establishing their own production base, Asian supermarkets prefer to purchase vegetables from the same intermediaries. A recent investigation of Walmart in China confirms this and reveals that Walmart has the same external suppliers as wet markets (Michelson et al., 2018). Supermarkets may hence not be superior in terms of guaranteeing vegetable safety.

While supermarkets are continuously expanding in developing countries, including China, several researchers have expressed their concern regarding the limits or potentially negative impacts of supermarket expansion (Polsa and Fan, 2011; Si et al., 2016; Watts et al., 2018; Wertheim-Heck et al., 2014). For instance, supermarkets may not fit into the traditional consumption pattern and lifestyle of the consumer (Rudawska and Bilinska-Reformat, 2018; Wertheim-Heck et al., 2015). Berger and van Helvoirt (2018) investigated the location of supermarkets in urban areas and found that supermarkets prefer wealthy neighborhoods. Previous studies have highlighted the regional disparity in China and revealed gaps in economic development between developed coastal cities (e.g. Shanghai and Beijing) and underdeveloped inland cities (Démurger, 2001; White et al., 2018; Zhan and Huang, 2017). Although Reardon and Hopkins (2006) claimed that supermarkets would expand from coastal urban areas to underdeveloped areas, this assumption has not yet been empirically confirmed.

This paper studies the impact of supermarketization on vegetable retail in urban China to answer the following question: to what extent do supermarkets improve vegetable safety? The research is implemented in four steps. The next section introduces the value chain governance approach developed by Gereffi et al. (2005) to categorize vegetable value chains in urban China into different types. Section three explains the data sources and methods. The dataset contains 1,393 observations from 17 cities in Shandong Province, based on publicly available data from the food safety reports of the Chinese Food and Drug Administration (CFDA). Factorial-logistic analysis is used to assess the impact of different value chain types on the prevalence of vegetable safety problems. Section four presents the empirical results. The last section discusses the limits of supermarketization and the comparison with other forms of vegetable supply.

\section{Conceptual framework: vegetable value chain types}

In this section, the value chain typology is introduced. The value chain approach developed by Gereffi et al. (2005) covers the chain segments and the governance structure in value chains. This analytical framework has been applied to the food industry to evaluate the food safety performance of different value chains. Following this perspective, food safety improvement is expected to result from the coordinated activities of the different actors producing and handling vegetables. Gereffi et al. (2009) distinguish five types of value chains according to their level of integration and the degree of power asymmetry between the following different segments of the value chain: market, modular, relational, captive and hierarchy. The logic behind this typology is that the more a value chain is governed through tight explicit coordination by a few consolidated actors, the more likely the value chain can implement comprehensive private standards to regulate food safety (Gereffi et al., 2009). This section will provide further background on retailer types and value chains in the Chinese vegetable sector and develop a typology for the Chinese context.

Supermarket chain stores have advantages in coping with complex transactions because they are under central coordination and comply with the private safety standards set by the corporation (Dries et al., 2014; Ruben et al., 2007). If supermarkets source vegetables from their own production base, then the value chain can be defined as a hierarchy, following Gereffi et al.'s typology (2005). The level of integration in the hierarchical chain is high. Own 
production bases can be established if the management of the corporation rents agricultural land and hires farmers to produce vegetables on the land or when an exclusive contract is signed with a farmer cooperative to secure a safe and continuous vegetable supply. In addition to supplying from own production bases, supermarket chains can source from external suppliers. Such external suppliers are often termed intermediaries and can include transporters, middlemen, traders and wholesalers (Timmer, 2009). Intermediaries purchase vegetables from farmers and sell to the retailer (Gereffi et al., 2005). The intermediaries are significantly smaller than supermarket chains in terms of size and sales volume. In these circumstances, supermarkets possess a large capacity in leveraging upstream suppliers, and this form of value chain governance tends toward the captive type (Gereffi et al., 2009).

In addition to supermarket chains, small-scale retailers in China can be differentiated into wet markets, grocery stores and local small-scale supermarkets (Babcock, 2017). Unlike a supermarket chain, a small-scale retailer is not superior to the intermediary in size or capacity; these retailers lack the human resources necessary to implement sampling and testing when purchasing vegetables from suppliers, and they generally cannot leverage the practices of their supplier (Goldman, 2001; Lu et al., 2008).

Stallholders in wet markets have been selling vegetables to urban residents since the 1980s. Before the 1980s, vegetables were delivered to urban residents by the state-run vegetable retail system (Goldman, 2001). After market liberalization, the centrally planned retail system disappeared and gave way to private retailers (Michelson et al., 2018). A typical formal wet market accommodates 20-100 stallholders. The allocation of stall sites, food safety control and other regulations are coordinated by a market administrator (Goldman, 2001). In the view of city governments, stallholders and street vendors are responsible for food safety hazards because of the limited capacity of wet markets in controlling food safety (Michelson et al., 2018).

Grocery stores are another important selling point for vegetables in China. Grocery stores used to be part of the centrally planned retail system and were privatized in the 1990s (Babcock, 2017). Grocery store holders are mostly self-employed, with fewer than eight employees (Goldman, 2001). The main difference from the wet market is that grocery stores have permanent premises located in an urban area. Unlike stallholders aggregated on the market grounds, grocery stores are widely dispersed across blocks and neighborhoods. Individual grocery stores possess limited human resources, which also limits them in controlling intermediaries and vegetable safety.

Finally, small-scale self-service stores play an important role in vegetable retail. These stores, commonly named "local supermarkets" or "independent supermarket", are generally small and operate only one outlet, different from a supermarket chain (Gale and $\mathrm{Hu}, 2012$ ). Local supermarkets differ from the grocery store by their comparatively larger sales and staff. Store sizes can reach 1,000 square metres with up to 50 employees, while grocery stores generally have fewer than eight staff members (Gale and Hu, 2012). For these reasons, a local supermarket is expected to have a higher capacity of securing food safety than a grocery store but a lower capacity than a supermarket chain. In most cases, a local supermarket relies on intermediaries when purchasing vegetables.

In conclusion, we distinguish four types of vegetable retailers and four value chain types. Supermarket chains are lead firms in either the hierarchical chain or the captive chain. In the hierarchical chain, all vegetable transactions occur under a unified standard and are implemented with central coordination. We therefore expect that the degree of vegetable safety is the highest in the hierarchical chain. In the captive chain, the supermarket chain is expected to have enough capital and human resources to "capture" its suppliers and modify suppliers' behavior. The intermediary relies on detailed instructions provided by the largescale supermarket chain. The captive chain is highly integrated and dominated asymmetrically by the supermarket chain. The degree of vegetable safety in the captive 
chain is therefore expected to be high but somewhat lower than that in the hierarchical chain because vegetable safety control is exerted indirectly.

Small-scale retailers can be coordinated through two other types of value chains. The small scale of these retailers does not allow them to exert control over their suppliers; hence, they cannot be categorized as leading either captive or hierarchical chains. The distinction in the type of value chain that they are involved in is based on whether they use an intermediary. In the case that an intermediary intervenes in the vegetable purchases of small-scale retailers, we assume the chain type to be relational, based on the similar sizes of the retailer and the intermediary; hence, there is the absence of a power asymmetry between the transaction partners. On the other hand, if small-scale retailers purchase vegetables directly from the rural spot market and thereby bypass the intermediary, we assume that the transaction occurs in a market-based type of value chain. Table 1 provides an overview of the retailer and value chain types that have been discussed. The degree of vegetable safety is expected to be the lowest in the market-based chain and to increase with increasing coordination along the chain or from left to right, as shown in Table 1.

\section{Empirical data and analysis}

\subsection{Data source}

Data for empirical analysis were collected from the food inspection reports conducted in 2017 by the "food safety risk monitoring system" (http://samr.cfda.gov.cn/WS01/CL1667/index_5. html). This monitoring system was established by the Chinese Food and Drug Administration (CFDA) following the new "Food Safety Law", which aimed to conduct food safety risk assessment, risk communication and early warning. It is a systematic and continuous collection of monitoring data and related information on foodborne diseases, food contamination and hazard factors in food. These officially published reports contain detailed information on the type of food safety hazard and allowed residue levels and inspection results. The main purpose of risk monitoring is to detect food safety hazards through randomly drawn representative samples from all food retailers. If the sample taken is found to be contaminated, the retailer faces administrative liabilities. The CFDA guarantees the use of the same safety standard in inspections for all types of retailers.

After retrieving all CFDA reports in 2017, we found 683 vegetable samples in 89 cities that are reported as "contamination detected". Figure 1 presents the geographical distribution of the observations in 89 cities across China. Each circle represents one of the cities in our dataset. Because the population varies greatly across cities, we needed to convert the original observation numbers. The size of the circles represents the number of detected observations in the city divided by the city population in million. Most cities in China are located in the Yellow River delta, the Yangtze River Delta and the coastal area. The north and east of the country have a lower population density and therefore fewer cities. The size of the circles varies enormously. The developed cities, such as Beijing and Shanghai, had lower rates of contamination than the other cities.

\begin{tabular}{lllll}
\hline $\begin{array}{l}\text { Value chain } \\
\text { type }\end{array}$ & Market-based chain & Relational chain & Captive chain & $\begin{array}{l}\text { Hierarchical } \\
\text { chain }\end{array}$ \\
\hline Supplier & Spot market & Intermediary & Intermediary & $\begin{array}{l}\text { Production } \\
\text { base }\end{array}$ \\
Retailer & $\begin{array}{l}\text { Wet market, grocery store, } \\
\text { local supermarket }\end{array}$ & $\begin{array}{l}\text { Wet market, grocery store, } \\
\text { local supermarket }\end{array}$ & $\begin{array}{l}\text { Supermarket } \\
\text { chain }\end{array}$ & $\begin{array}{l}\text { Supermarket } \\
\text { chain }\end{array}$
\end{tabular}

Source(s): Based on Gereffi et al. (2005)

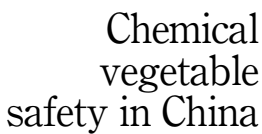

Chemical safety in China

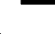




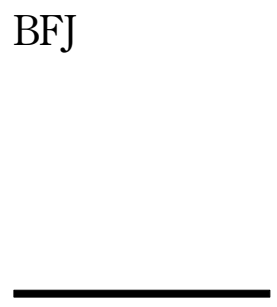

Figure 1.

Geographical distribution of contaminated samples in Chinese cities

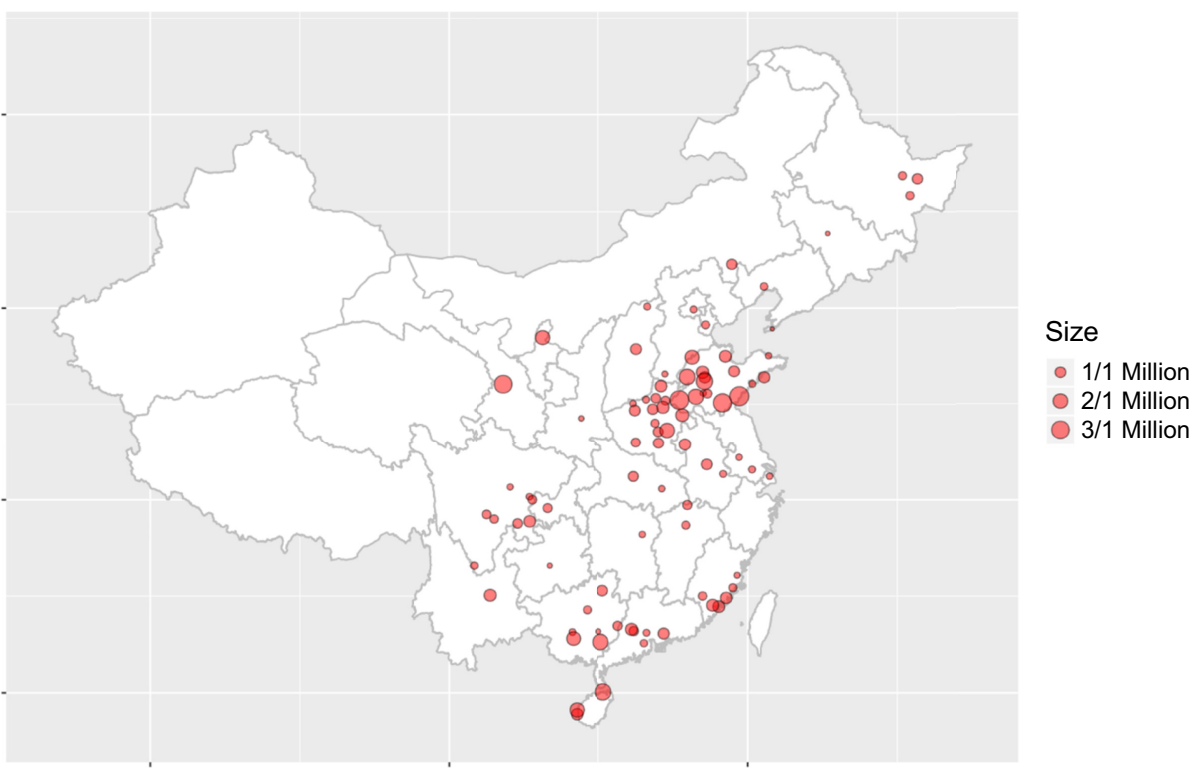

Note(s): Each circle in Figure 1 represents one city. The circle size indicates the number of contamiated samples found in the city divided by the city population in million

Source(s): Based on CFDA report in 2017

Figure 2 reveals a significant correlation between economic development and vegetable safety degree by showing that cities with a higher GDP per capita have fewer observations of food safety hazard detections (correlation coefficient is -0.007 and significant at $p<0.01$ ). In short, vegetable safety hazards are prevalent in urban China. In addition, the safety degree is even lower in economically underdeveloped cities. In the empirical analysis, we will attempt to reveal the impact of supermarketization on vegetable safety in different cities.

However, risk monitoring is implemented by the provincial division of the CFDA, and the executive ability of different provincial divisions may vary, which may affect the quality of the reports. The reports in some provinces are found to be ambiguous or to lack key information, such as the name of the retailer. After comparing the reports in 31 provincial divisions, we selected Shandong Province, among others, for its high data quality.

\subsection{Overview of the dataset in Shandong Province}

Shandong Province is one of the main vegetable producers in China, with a total output of 97 million tons. The vegetable consumption in Shandong is fulfilled by local production. The economic development of Shandong (GDP per capita in 2017: 10,303 US dollars) is slightly above average in China (8,643 US dollars), ranking 10th out of 31 provinces. Shandong Province has a population of 98 million, of which $57 \%$ live in urban areas (NBSC, 2017). Seventeen cities in Shandong Province are fully covered in the monitoring system. According to the CFDA, monitoring samples are taken randomly. To validate the dataset, we checked the correlation between the number of monitoring reports and the city population, and the result indicates high correlation. This confirms that more samples were taken in larger cities. 


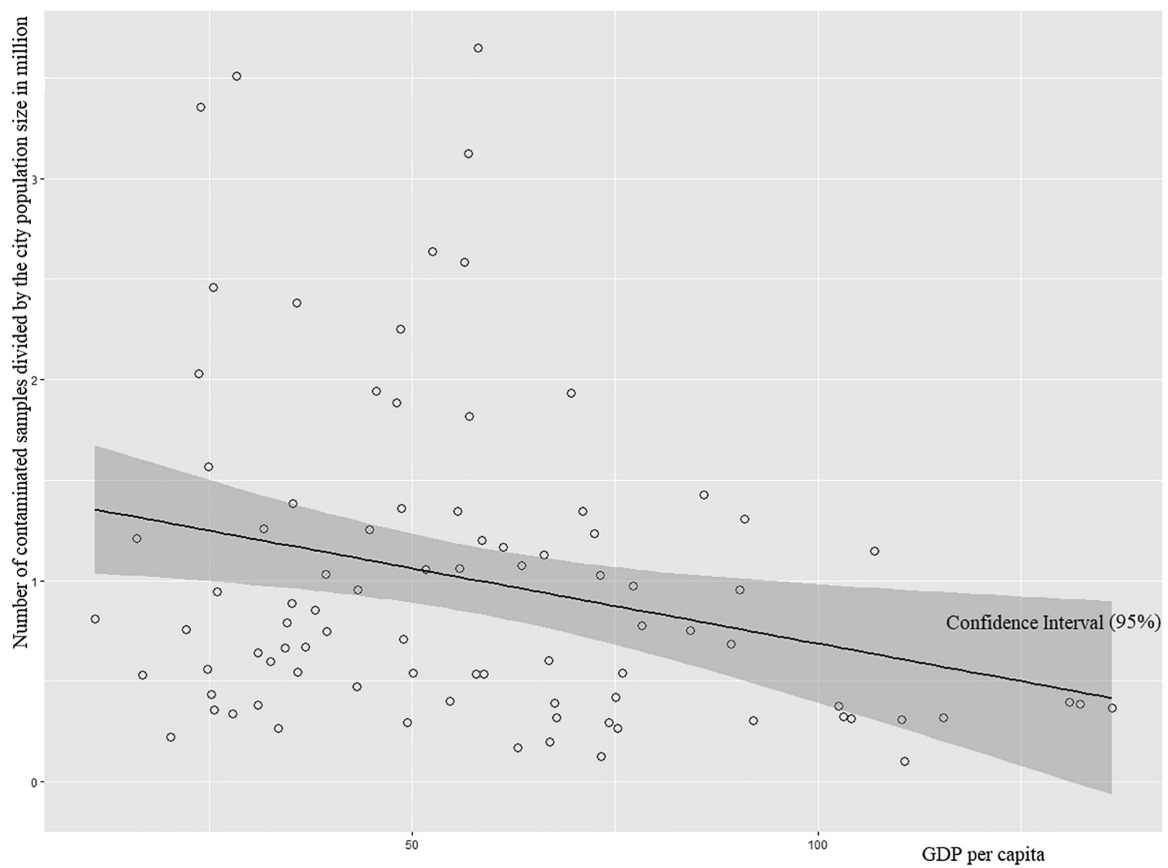

Note(s): One circle in Figure 2 represents one city. The unit associated with the $\mathrm{X}$ axis is the city GDP per capita in 1,000 Yuan. The unit associated with the $\mathrm{Y}$ axis is the number of contaminated vegetable samples in the city divided by the city population size in million

Source(s): Based on CFDA report in 2017

\section{Chemical vegetable safety in China}

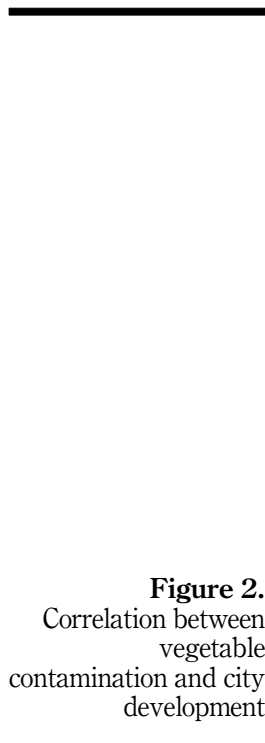

The CFDA reports contain the following information (see Table 2 for an overview of variables and summary statistics): food safety status (contamination detected/nondetected); name and address of the retailer as recorded during the inspection; intermediary's name given by the retailer and date of purchase. Our dataset contains 1,393 vegetable samples, of which 144 were reported as "detected", 141 with "excessive pesticide residue" and 3 with "heavy metal residue". Similar to the European Food Safety Authority (EFSA), the CFDA applies a general default MRL of $0.01 \mathrm{mg} / \mathrm{kg}$ (WHO, 2016). In addition, the reports include information about the vegetable type. Following an FAO report on pesticide residues, we group vegetables into four classes as follows: leafy or stem vegetables; fruit-bearing vegetables; root, bulb, or tuberous vegetables and mushrooms (FAO, 2018). The observations are also divided into four seasons based on the date of inspection.

Intermediaries are classified into two categories based on their size, measured by the number of employees. If the intermediary is registered as a corporation in the CFDA reports ("corporate"), it has at least eight employees. A "trader", on the other hand, is a self-employed individual with fewer than eight employees. Retailers are grouped into four categories according to the typology introduced in the previous section.

Some limitations should be kept in mind with respect to the dataset. First, the volume of vegetable sales in supermarket chains is generally much larger than the sales volume of smallscale retailers; hence, supermarket chains could be underrepresented in the sample. Unfortunately, we do not have information about the sales volume of different retailers. Without a reliable data source for this information, we are not able to weigh the data. Second, the 
$\mathrm{BFJ}$

\begin{tabular}{|c|c|c|c|}
\hline Variable & Specification & Number of observation & Percentage of the sample $(n=1,393)$ \\
\hline \multirow[t]{2}{*}{ Safety } & Detected & 144 & $10.3 \%$ \\
\hline & Nondetected & 1,249 & $89.7 \%$ \\
\hline \multirow[t]{2}{*}{ Intermediary } & Trader & 463 & $33.2 \%$ \\
\hline & Corporate & 162 & $11.6 \%$ \\
\hline \multicolumn{2}{|c|}{ Without intermediary } & 768 & $55.1 \%$ \\
\hline \multirow[t]{4}{*}{ Retailer } & Wet market & 338 & $24.3 \%$ \\
\hline & Grocery store & 231 & $16.6 \%$ \\
\hline & Local supermarket & 350 & $25.1 \%$ \\
\hline & Supermarket chain & 474 & $34.0 \%$ \\
\hline \multirow[t]{4}{*}{ Vegetable } & Leafy or stem & 714 & $51.3 \%$ \\
\hline & Fruit-bearing & 396 & $28.4 \%$ \\
\hline & Root, bulb & 223 & $16.0 \%$ \\
\hline & Mushrooms & 60 & $4.3 \%$ \\
\hline \multirow[t]{4}{*}{ Season } & Spring & 219 & $15.7 \%$ \\
\hline & Summer & 3 & $0.2 \%$ \\
\hline & Fall & 493 & $35.4 \%$ \\
\hline & Winter & 678 & $48.7 \%$ \\
\hline
\end{tabular}

Table 2.

Overview of the dataset for Shandong Province

Source(s): Based on CFDA reports in 2017

variation within retailer types is neglected. We put retailers with various features into four categories and treat the retailers within each type as homogeneous, even though their capacity to control food safety could vary. Third, all vegetable safety hazards are treated in the same way in the dataset, regardless of possible differences in the toxicity of residues and contaminations.

\subsection{The model for empirical analysis}

A logistic regression model is used to test the hypothesis that the degree of food safety differs between value chain types. $\mathrm{R}$ is applied in the empirical analysis. We used standard $\mathrm{R}$ packages to guarantee the reliability of the empirical result. Figures 1 and 2 were drawn with the ggplot2 package. The logistic model was estimated with the glm package. The response variable is a dummy variable: "contamination detected" has value 1 and "no contamination detected" has value zero. The independent variables are categorical. The retailer variable has four values as follows: wet market, grocery store, local supermarket and supermarket chain. The intermediary variable has three values as follows: without intermediary has value zero, individual trader has value 1 and corporate trader has value 2 . The value chain variable has four values based on the combination of intermediary and retailer type as follows: marketbased value chain, relational value chain, captive value chain and hierarchical value chain. Figure 3 illustrates the 11 combinations of retailer and intermediary and links the combinations to four value chain types. To ensure the robustness of the empirical analysis, we added three control variables, which are also categorical variables. The season variable has four values, namely the four seasons. The vegetable type variable has four values as follows: leafy, root, mushroom and fruit-bearing. The following empirical model is estimated:

$$
\begin{aligned}
\text { Safety }= & b_{0}+b_{1} * \text { value chain }+b_{2} * \text { intermediary }+b_{3} * \text { retailer }+b_{4} * \text { vegetable } \\
& +b_{5} * \text { season }+b_{6} * \text { city }+\epsilon
\end{aligned}
$$

where city represents the fixed effects for each of the 17 cities in Shandong Province to incorporate potential differences between cities, such as the quality of monitoring divisions, that could influence vegetable safety results but that are not captured by the other variables in the model, and $\epsilon$ is the error term. 


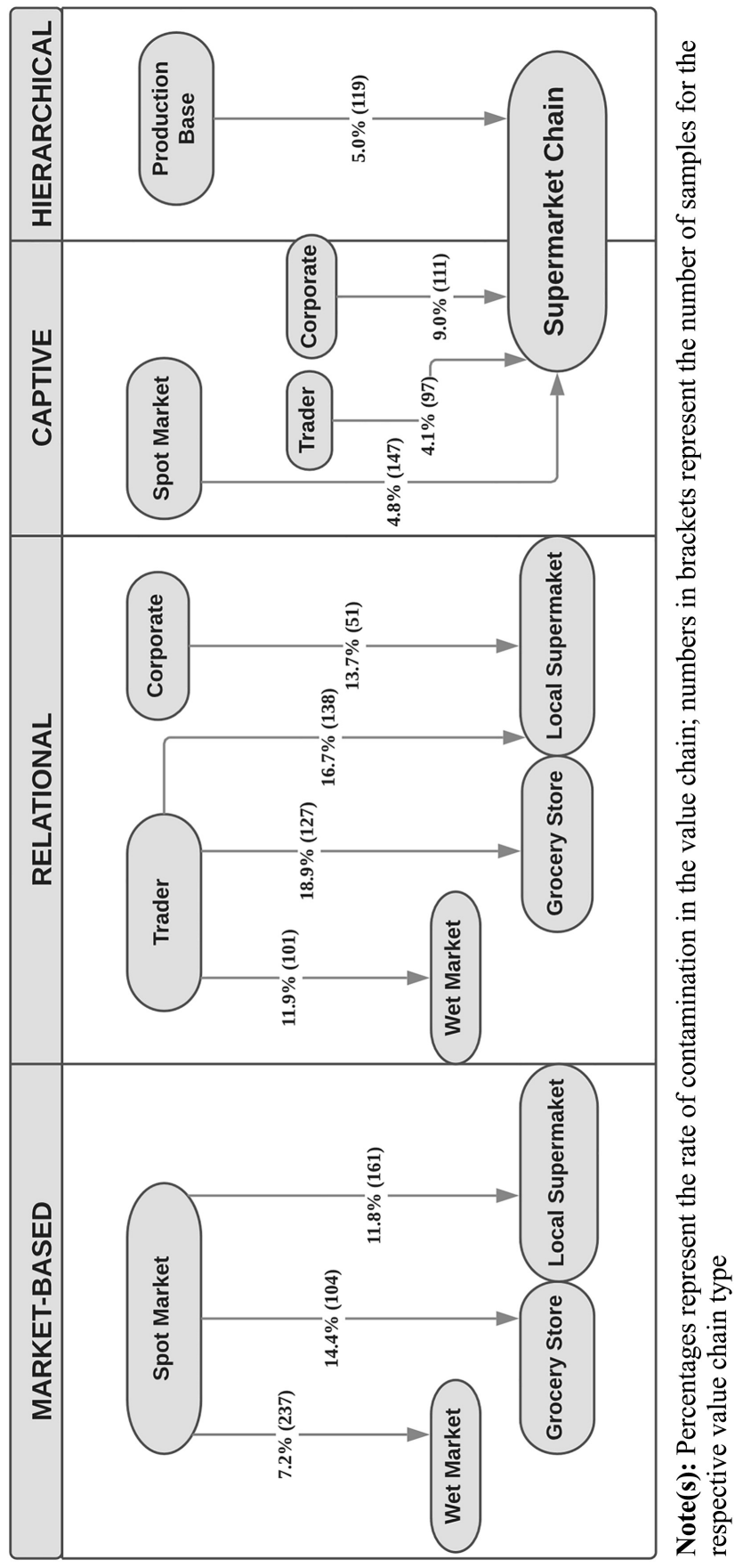

Chemical vegetable safety in China

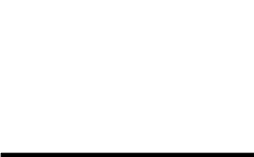

Figure 3.

Flow of vegetables in value chains and contamination rates 
We use Pearson's goodness of fit to test whether the model fits the data distribution. The result of the test is significant $(P<0.001)$. Thus, we conclude that the logistic model is appropriate for the data distribution. To test the collinearity of predict variables, we conduct the correlation coefficient matrix in Table A1. We confirmed that the explanatory variables have no significant multicollinearity, except for the value chain and retailer because the value chain is calculated based on the retailer and intermediary.

\section{Results}

4.1 Value chain types and food safety

Figure 3 shows the different retailer and value chain types defined in section 2 and their respective "detected rate of food contamination". In total, 474 samples were taken in supermarket chains, of which 355 belong to the captive chain type, and 119 samples could be classified as the hierarchical chain type. As expected, the captive and hierarchical chains supply a higher degree of vegetable safety than the other chain types. The "relational chain", including 417 samples, seems to perform the worst with respect to vegetable safety. The next section will present the results of the logistic regression to test the significance of these variations.

\subsection{Supermarketization, value chain reorganization and food safety}

Table 3 shows the regression results for vegetable safety and predict variables. To ensure the robustness of the results, four models are tested with different specifications of the

\begin{tabular}{|c|c|c|c|c|}
\hline Variables & Model 1 & Model 2 & Model 3 & Model 4 \\
\hline \multicolumn{5}{|l|}{ Value chain } \\
\hline Market-based & $-0.761(0.475)$ & $-0.841(0.453)$ & & \\
\hline Relational & $-1.546(0.471)^{* *}$ & $-1.406(0.450)^{* *}$ & & \\
\hline Captive & $-0.334(0.502)$ & $-0.346(0.484)$ & & \\
\hline Hierarchical & - & - & & \\
\hline \multicolumn{5}{|l|}{ Retailer } \\
\hline Wet market & & & $-0.491(0.315)$ & $-0.411(0.301)$ \\
\hline Grocery store & & & $-1.181(0.312)^{* * * *}$ & $-1.164(0.299)^{\text {**** }}$ \\
\hline Local supermarket & & & $-0.896(0.280)^{* * * *}$ & $-0.957(0.266)^{\text {**** }}$ \\
\hline Supermarket chain & & & - & - \\
\hline \multicolumn{5}{|l|}{ Intermediary } \\
\hline Trader & & & $-0.659(0.222)^{*}$ & $-0.419(0.204)^{*}$ \\
\hline Corporate & & & $-0.548(0.339)$ & $-0.310(0.210)$ \\
\hline Without & & & - & - \\
\hline \multicolumn{5}{|l|}{ Season } \\
\hline Spring & $0.659(0.293)^{*}$ & $0.375(0.264)$ & $0.654(0.291)^{*}$ & 0.377 (0.263) \\
\hline Summer & $-3.358(1.328)^{*}$ & $-3.697(1.304)^{* *}$ & $-3.283(1.373)^{*}$ & $-3.480(1.250)^{* *}$ \\
\hline Fall & $0.858(0.235)^{* * * *}$ & $0.826(0.228)^{* * * *}$ & $0.900(0.239)^{* * *}$ & $0.879(0.230)^{* * * *}$ \\
\hline Winter & - & - & - & - \\
\hline \multicolumn{5}{|l|}{ Type } \\
\hline Fruit-bearing & $-0.576(0.499)$ & $-0.590(0.497)$ & $-0.551(0.497)$ & $-0.569(0.495)$ \\
\hline Leafy & $-1.853(0.446)^{* * *}$ & $-1.914(0.445)^{* * *}$ & $-1.821(0.444)^{* * *}$ & $-1.883(0.441)^{\text {*** }}$ \\
\hline Mushroom & $-0.696(0.688)$ & $-0.685(0.682)$ & $-0.657(0.692)$ & $-0.611(0.688)$ \\
\hline Root & - & - & - & - \\
\hline City-fixed effect & yes & no & yes & no \\
\hline
\end{tabular}

Table 3.

Regression results: retailer, value chain type and vegetable safety 
independent variables. Model 1 is the model including value chain type and all control variables. We find that the city variable has no significant correlation with the response variable. In model 2 , we have therefore dropped city. The results in model 2 remain consistent with model 1. Models 3 and 4 use retailer type and intermediary as independent variables. Model 3 was conducted including all control variables. Again, the variable city is the only insignificant variable. We therefore remove the city variable in model 4 . All results show to be robust to this change in the model specification.

In models 1 and 2 , we intend to compare the possibility of contamination in different value chains. We use the hierarchical chain as the baseline of comparison. An observation taken from the relational chain has a significantly higher probability of being contaminated compared to an observation from the hierarchical chain, holding all other variables constant. The hierarchical chain also performs better than the captive and market-based chains, but these results are not significant. Models 3 and 4 provide robust evidence that supermarket chains perform significantly better in vegetable safety compared to local supermarkets and grocery stores. Surprisingly, the incidence of vegetable safety problems is not significantly higher in wet markets compared to that in supermarket chains. Another result from these models is that chains including intermediaries - either individual or corporate traders - seem to perform worse in vegetable safety compared to chains without intermediaries, but these results are not significant.

Table 4 investigates the degree of vegetable safety in the different chains presented in Figure 1, in more detail. The hierarchical chain is selected as the baseline. All value chain combinations perform significantly worse in the market-based and relational chains than in the hierarchical chain except for the combinations including the wet market. As expected, the results also show that the vegetable safety degree in the captive chain is not significantly different from that in the hierarchical chain (see Table 5).

\subsection{Supermarketization at the provincial scale}

The results in Sections 4.1 and 4.2 confirm the expectation that the supermarket chain has the highest level of vegetable safety. A question that remains is whether supermarket chains have been established in the whole province, and in particular, in cities with different levels of development. First, the market share of supermarket chains is not significantly correlated with the economic development of the city $(p$-value $=0.522)$. Second, detection

\begin{tabular}{|c|c|c|c|}
\hline Variables & Model 1 & Model 2 & \\
\hline \multicolumn{4}{|l|}{ Value chain } \\
\hline $\begin{array}{l}\text { Market-based } \\
\text { Spot market-wet market } \\
\text { Spot market-grocery store } \\
\text { Spot market-local supermarket }\end{array}$ & $\begin{array}{l}-0.375(0.488) \\
-1.155(0.503)^{*} \\
-0.924(0.485)^{*}\end{array}$ & $\begin{array}{l}-0.446(0.512) \\
-1.313(0.552)^{*} \\
-0.790(0.531)\end{array}$ & \\
\hline $\begin{array}{l}\text { Relational } \\
\text { Trader-wet market } \\
\text { Trader-grocery store } \\
\text { Trader-local supermarket } \\
\text { Corporate-local supermarket }\end{array}$ & $\begin{array}{l}-0.932(0.519)^{* *} \\
-1.479(0.476)^{* *} \\
-1.326(0.477)^{* *} \\
-1.097(0.584)^{*}\end{array}$ & $\begin{array}{l}-1.205(0.572)^{*} \\
-1.737(0.506)^{* * * *} \\
-1.757(0.523)^{* * * *} \\
-1.158(0.627)^{*}\end{array}$ & \\
\hline $\begin{array}{l}\text { Captive } \\
\text { Spot market-supermarket chain } \\
\text { Trader-supermarket chain } \\
\text { Corporate-supermarket chain }\end{array}$ & $\begin{array}{r}0.060(0.570) \\
0.211(0.660) \\
-0.623(0.534)\end{array}$ & $\begin{array}{r}0.029(0.608) \\
0.179(0.688) \\
-0.736(0.560)\end{array}$ & $\begin{array}{r}\text { Table } 4 . \\
\text { Regression results: } \\
\text { value chain } \\
\text { combination and }\end{array}$ \\
\hline \multicolumn{4}{|c|}{ Note(s): Standard errors are reported in parentheses; Significance levels: $* * * p<0.01, * * p<0.05, * p<0.10$} \\
\hline
\end{tabular}




\begin{tabular}{|c|c|c|c|c|c|}
\hline BFJ & City & Total & Detected rate & Supermarket chain share & GDP per capita (Yuan) \\
\hline & Dongying & 75 & $5.3 \%$ & $37.3 \%$ & 116,448 \\
\hline & Weihai & 73 & $11.0 \%$ & $30.1 \%$ & 106,922 \\
\hline & Qingdao & 72 & $9.7 \%$ & $37.5 \%$ & 102,519 \\
\hline & Yantai & 64 & $3.1 \%$ & $67.2 \%$ & 91,979 \\
\hline & Zibo & 55 & $9.1 \%$ & $21.8 \%$ & 89,235 \\
\hline & Jinan & 91 & $13.2 \%$ & $38.5 \%$ & 85,919 \\
\hline & Binzhou & 75 & $10.7 \%$ & $14.7 \%$ & 61,189 \\
\hline & Rizhao & 59 & $13.6 \%$ & $52.5 \%$ & 58,111 \\
\hline & Taian & 92 & $16.3 \%$ & $27.2 \%$ & 56,491 \\
\hline & Weifang & 110 & $7.3 \%$ & $65.5 \%$ & 55,824 \\
\hline & Zaozhuang & 76 & $5.3 \%$ & $22.4 \%$ & 52,692 \\
\hline & Laiwu & 90 & $2.2 \%$ & $14.4 \%$ & 49,377 \\
\hline & Jining & 113 & $13.3 \%$ & $31.0 \%$ & 48,529 \\
\hline & Dezhou & 64 & $9.4 \%$ & $25.0 \%$ & 48,062 \\
\hline & Liaocheng & 87 & $16.1 \%$ & $36.8 \%$ & 35,754 \\
\hline & Heze & 90 & $11.1 \%$ & $30.0 \%$ & 28,351 \\
\hline Table 5 & Linyi & 107 & $15.0 \%$ & $26.2 \%$ & 23,896 \\
\hline
\end{tabular}

City-level Note(s): Supermarket chain share is the number of samples from supermarket chains divided by the total aggregated data number, which is based on the CFDA reports

rates of vegetable safety problems vary from $2.2 \%$ to $16.1 \%$ but are also not significantly correlated with the GDP per capita $(p$-value $=0.402)$. Finally, the correlation between the market share of a supermarket chain and the food safety detection rate is not significant $(\phi$-value $=0.389)$.

\section{Discussion: moving beyond supermarketization}

\subsection{Supermarkets and hierarchical chains lead to higher vegetable safety}

The empirical results indicate that the hierarchical value chain provides vegetables at the highest safety degree. This result confirms the hypothesis that a higher level of chain integration leads to more food safety. In the literature, the explanation for this observation is that the high integration level reduces transaction costs and thereby contributes to the efficient flow of information between producers and supermarkets (Ding et al., 2015). More specifically, previous research claims that supermarket managers or the management of the retail corporation conveys knowledge about standards, monitor the production process and coordinate the amount of pesticide application. These measures reduce pesticide residues and hence improve food safety (Ding et al., 2015).

\subsection{Supermarkets and intermediaries}

In addition, our empirical results show a high degree of vegetable safety in the captive chain. Although vegetables in the captive chain are purchased from intermediaries, the safety degree is not significantly lower than that in the hierarchical chain. This result does not correspond with previous observations. Goldman (2001), for instance, placed doubts on vegetable safety in supermarket chains because supermarkets buy from intermediaries that aggregate vegetables from farmers and sell to supermarket chains as well as to grocery stores and wet markets. The high safety degree found in supermarket chains in the current study can be explained in two ways. Supermarket chains may be able to identify and capture intermediaries that provide safer vegetables because of supermarkets' higher capacity of safety inspection. Alternatively, intermediaries may choose to selectively supply high-quality 
and safer vegetables to supermarket chains because they see supermarket chains as their primary partner due to the volume of purchases (Michelson et al., 2018). According to this perspective, wet markets and grocery stores are considered residual outlets for excess vegetables or vegetables that do not meet the quality standards of supermarkets.

However, the overall safety degree of value chains involving intermediaries is significantly lower than that of value chains without an intermediary. Other research suggests that, in addition to contributing to the flow of goods, intermediaries are expected to facilitate the flow of information, coordinate with farmers, provide inputs such as pesticides and guide farmers in pesticide application (Lu et al., 2008). If such additional services were present, then intermediaries could be expected to have a positive influence on vegetable safety. However, our results show that this is not the case. This observation could be explained because intermediaries lack the direct motivation to provide support for farmers and improve coordination in the value chain. Moreover, because of the mobility of intermediaries between rural and urban areas, intermediaries may be harder for the public authority to inspect. In practice, CFDA safety inspection targets only the retailer, and intermediaries are not directly inspected. It should be noted that this study is based on a simplified notion of the value chain and is abstracted from potential differences between intermediaries. Further research may therefore be needed to determine the true role and influence of intermediaries on the value chain and farmers' practices regarding pesticide use in particular.

\subsection{A high safety degree in wet markets}

Our empirical results show that the wet market provides significantly safer vegetables than other small-scale retailers. This unexpected result can be explained in different ways. First, most stallholders are highly specialized and concentrate on selling either vegetables, fruits or aquaculture products. This specialization may enhance the stallholders' capacity to control vegetable safety. Stallholders in the wet market purchase vegetables very early in the morning and constantly trim, spray, clean and sort the vegetables to keep them fresh. In addition, stallholders have no cold chain for storage and thus have to replenish their inventory with fresh supplies daily (Maruyama et al., 2016; Suryadarma et al., 2010). Throughout China, local governments have also launched renovation programmes for wet markets in response to urban residents' preferences for buying fresh products from wet markets. In Shanghai and Nanjing, the city government has upgraded the existing wet markets by providing better rapid pesticide testing equipment, offering free food safety training for stallholders and upgrading storage facilities. Previous research in Shanghai confirmed that this upgrade has improved the facilities and hygiene in wet markets. Although there is no detailed evaluation of this wet market upgrade in Shandong, it is possible that this policy has contributed to vegetable safety improvement. In addition, stallholders may benefit from information sharing with peers in the wet market, where a large number of stallholders aggregate in one space, facilitating the knowledge sharing regarding food safety.

\section{Conclusion}

In this paper, we investigated supermarketization in the vegetable retail sector and its impact on vegetable safety. Supermarket chains have expanded rapidly in urban China with governmental support in recent decades. Supermarketization leads to the reorganization of the vegetable provision system with the emergence of production bases and closer coordination with intermediaries. Following the global value chain approach of Gereffi, we identified four types of value chains based on their level of 
integration and coordination. To assess the vegetable safety degree of each value chain type, we used data from CFDA public reports. A regression analysis confirmed that the hierarchical chain and the captive chain performed better than the other value chain types in terms of vegetable safety. Surprisingly, the research also showed a high degree of vegetable safety in wet markets. Based on this empirical result, wet markets may also play a role in solving the vegetable safety problem in the future, especially in underdeveloped areas that are not yet covered by supermarket chains. More in-depth research on wet markets is needed to support this claim.

\section{References}

Babcock, T. (2017), “Annual retail foods report - China”, available at: https://gain.fas.usda.gov/Recent GAIN Publications/Retail Foods_Beijing ATO_China - Peoples Republic of_1-26-2017.pdf (accessed 6 November 2019).

Berger, M. and van Helvoirt, B. (2018), "Ensuring food secure cities - retail modernization and policy implications in Nairobi, Kenya", Food Policy, Elsevier, Vol. 79 No. February, pp. 12-22.

Cheng, L., Jiang, S., Zhang, S., You, H., Zhang, J., Zhou, Z., Xiao, Y., Liu, X., Du, Y., Li, J., Wang, X., Xin, Y., Zheng, Y. and Shang, K. (2016), "Consumers' Behaviors and Concerns on Fresh Vegetable Purchase and Safety in Beijing Urban Areas, China”, Food Control, Vol. 63, pp. 101-109.

Démurger, S. (2001), "Infrastructure development and economic growth: an explanation for regional disparities in China?", Journal of Comparative Economics, Vol. 29 No. 1, pp. 95-117.

Ding, J., Huang, J., Jia, X., Bai, J., Boucher, S. and Carter, M. (2015), "Direct farm, production base, traceability and food safety in China", Journal of Integrative Agriculture, Elsevier, Vol. 14 No. 11, pp. 2380-2390.

Dries, L., Gorton, M., Urutyan, V. and White, J. (2014), "Supply chain relationships, supplier support programmes and stimulating investment: evidence from the Armenian dairy sector", Supply Chain Management, Vol. 19 No. 1, pp. 98-107.

Dries, L., Reardon, T. and Swinnen, J.F.M. (2004), "The rapid rise of supermarkets in central and Eastern Europe: implications for the agrifood sector and rural development", Development Policy Review, Vol. 22 No. 5, pp. 525-556.

FAO (2018), "Transition towards sustainable food and agriculture", available at: http://www.fao.org/ in-action/agronoticias/detail/en/c/1118765/ (accessed 6 November 2019).

Gale, H.F. and Hu, D. (2012), "Food safety pressures push integration in China's agricultural Sector", American Journal of Agricultural Economics, Vol. 94 No. 2, pp. 483-488.

Gereffi, G., Humphrey, J. and Sturgeon, T. (2005), "The governance of global value chains”, Review of International Political Economy, Vol. 12 No. 1, pp. 78-104.

Gereffi, G., Lee, J. and Christian, M. (2009), "US-based food and agricultural value chains and their relevance to healthy diets", Journal of Hunger and Environmental Nutrition, Vol. 4 Nos 3-4, pp. $357-374$.

Goldman, A. (2001), "Supermarkets in China: the case of Shanghai", The International Review of Retail, Distribution and Consumer Research, Vol. 10 No. 1, pp. 1-21.

Kirezieva, K., Bijman, J., Jacxsens, L. and Luning, P.A. (2016), "The role of cooperatives in food safety management of fresh produce chains: case studies in four strawberry cooperatives", Food Control, Elsevier, Vol. 62, pp. 299-308.

Liu, P. and Ma, L. (2016), "Food scandals, media exposure, and citizens' safety concerns: a multilevel analysis across Chinese cities", Food Policy, Elsevier, Vol. 63, pp. 102-111.

Lu, H., Trienekens, J.H., Omta, S.W.F. and Feng, S. (2008), "The value of guanxi for small vegetable farmers in China", British Food Journal, Vol. 110 Nos 4-5, pp. 412-429.

Maruyama, M., Wu, L. and Huang, L. (2016), "The modernization of fresh food retailing in China: the role of consumers", Journal of Retailing and Consumer Services, Elsevier, Vol. 30, pp. 33-39. 
Michelson, H., Boucher, S., Cheng, X., Huang, J. and Jia, X. (2018), "Connecting supermarkets and farms: the role of intermediaries in Walmart China's fresh produce supply chains", Renewable Agriculture and Food Systems, Vol. 33 No. 1, pp. 47-59.

NBSC (2017), “China statistical yearbook 2017", available at: http://www.stats.gov.cn/english/ (accessed 18 February 2019).

OECD (2018), “OECD-FAO agricultural outlook 2018-2027”, OECD, 3 July, doi: 10.1787/agr_outlook2018-en.

Oosterveer, P. (2012), "Sustainability and supermarkets", in Spaargaren, G., Oosterveer, P. and Loeber, A. (Eds), Food Practices in Transition: Changing Food Consumption, Retail and Production in the Age of Reflexive Modernity, Routledge, London, pp. 153-176.

Polsa, P. and Fan, X. (2011), "Globalization of local retailing: threat or opportunity?: the case of food retailing in guilin, China", Journal of Macromarketing, Vol. 31 No. 3, pp. 291-311.

Reardon, T. and Hopkins, R. (2006), "The supermarket revolution in developing countries: policies to address emerging tensions among supermarkets, suppliers and traditional retailers", European Journal of Development Research, Vol. 18 No. 4, pp. 522-545.

Reardon, T. and Timmer, C.P. (2012), "The economics of the food system revolution”, Annual Review of Resource Economics, Annual Reviews, Vol. 4 No. 1, pp. 225-264.

Ruben, R., Boselie, D. and Lu, H. (2007), "Vegetables procurement by Asian supermarkets: a transaction cost approach", Supply Chain Management, Vol. 12 No. 1, pp. 60-68.

Rudawska, E.D. and Bilinska-Reformat, K. (2018), "The development of food retail formats - evidence from Poland", British Food Journal, Vol. 120 No. 2, pp. 309-324.

Si, Z., Scott, S. and Mccordic, C. (2016), "Supermarkets, wet markets and food patronage in Nanjing, China", Waterloo, doi: 10.2320/matertrans.43.1298.

Song, W., Schein, D.D. and Ravi, S.P. (2012), "The development of Chinese supermarket enterprise own brands: the case of Shanghai", International Journal of Management and Enterprise Development, Vol. 12 No. 2, p. 93.

Suryadarma, D., Poesoro, A., Budiyati, S., Rosfadhila, M. and Suryahadi, A. (2010), "Traditional food traders in developing countries and competition from supermarkets: evidence from Indonesia”, Food Policy, Elsevier, Vol. 35 No. 1, pp. 79-86.

Timmer, C.P. (2009), "Do supermarkets change the food policy agenda?", World Development", Elsevier, Vol. 37 No. 11, pp. 1812-1819.

Van Hoi, P., Mol, A.P.J. and Oosterveer, P. (2010), "Pesticide governance in export supply chains: the case of vegetable and fruit production in Vietnam", Environment and Planning C: Government and Policy, Vol. 28 No. 1, pp. 97-111.

Wang, S., Wang, Z., Zhang, Y., Wang, J. and Guo, R. (2013), "Pesticide residues in market foods in Shaanxi Province of China in 2010", Food Chemistry, Vol. 138 Nos 2-3, pp. 2016-2025.

Watts, D., Little, J. and Ilbery, B. (2018), "I Am pleased to shop somewhere that is fighting the supermarkets a little bit'. A cultural political economy of alternative food networks", Geoforum, Elsevier, Vol. 91 No. January, 2017, pp. 21-29.

Wertheim-Heck, S.C.O. and Spaargaren, G. (2016), "Shifting configurations of shopping practices and food safety dynamics in hanoi, Vietnam: a historical analysis", Agriculture and Human Values, Springer Netherlands, Vol. 33 No. 3, pp. 655-671.

Wertheim-Heck, S.C.O., Spaargaren, G. and Vellema, S. (2014), "Food safety in everyday life: shopping for vegetables in a rural city in Vietnam", Journal of Rural Studies, Elsevier, Vol. 35, pp. 37-48.

Wertheim-Heck, S.C.O., Vellema, S. and Spaargaren, G. (2015), "Food Safety and urban food markets in Vietnam: the need for flexible and customized retail modernization policies", Food Policy, Elsevier, Vol. 54, pp. 95-106. 
White, D.J., Hubacek, K., Feng, K., Sun, L. and Meng, B. (2018), “The water-energy-food nexus in east asia: a tele-connected value chain analysis using inter-regional input-output analysis", Applied Energy, Elsevier, Vol. 210, pp. 550-567.

WHO (2016), "Promoting fruit and vegetable consumption around the world", Global Strategy on Diet, Physical Activity and Health: Information Sheet, doi: 10.1097/NT.0b013e31826c50af.

Xu, R., Kuang, R., Pay, E., Dou, H. and de Snoo, G.R. (2008), "Factors contributing to overuse of pesticides in western China", Environmental Sciences, Vol. 5 No. 4, pp. 235-249.

Zhan, S. and Huang, L. (2017), "Internal spatial fix: China's geographical solution to food supply and its limits", Geoforum, Elsevier, Vol. 85 No. February, pp. 140-152.

Zhang, M., Jin, Y., Qiao, H. and Zheng, F. (2017), "Product quality asymmetry and food safety: investigating the 'one farm household, two production systems' of fruit and vegetable farmers in China”, China Economic Review, Elsevier, Vol. 45 No. July, pp. 232-243.

Zhao, L., Wang, C., Gu, H. and Yue, C. (2018), "Market Incentive, government regulation and the behavior of pesticide application of vegetable farmers in China", Food Control, Elsevier, Vol. 85, pp. 308-317.

Zhou, J.H., LI, K. and Liang, Q. (2015), "Food safety controls in different governance structures in China's vegetable and fruit industry", Journal of Integrative Agriculture, Chinese Academy of Agricultural Sciences, Vol. 14 No. 11, pp. 2189-2202. 
Appendix

Chemical vegetable safety in China

\begin{tabular}{lccccccr}
\hline & Retailer & Intermediary & Value chain & Type & Season & City & \\
\hline Retailer & 1.000 & 0.010 & 0.690 & 0.040 & 0.053 & 0.032 & \\
Intermediary & 0.010 & 1.000 & 0.231 & 0.015 & 0.085 & 0.085 & \\
Value chain & 0.690 & 0.231 & 1.000 & 0.041 & 0.064 & 0.094 & 0.105 \\
Type & 0.040 & 0.015 & 0.041 & 1.000 & 0.058 & 0.153 & Correlation coefficient \\
Season & 0.053 & 0.085 & 0.064 & 0.058 & 1.000 & 1.000 & matrix of explanatory \\
City & 0.032 & 0.085 & 0.094 & 0.105 & 0.153 & & variables \\
Source(s): Based on CFDA reports in 2017 & & & & & &
\end{tabular}

\section{Corresponding author}

Lita Alita can be contacted at: lita.a@wur.nl

For instructions on how to order reprints of this article, please visit our website:

www.emeraldgrouppublishing.com/licensing/reprints.htm

Or contact us for further details: permissions@emeraldinsight.com 